\section{El verde en la estructura urbana de Mendoza}

Una de las cualidades ambientales características de la ciudad de Mendoza es resultado de la asociación entre un sistema de riego elemental, cuyo origen se remonta a las primeras buertas precolombinas, y la arborización urbana. En un contexto climático más bien árido, la aparición del arbolado en las calles fue decisiva en la apropiación del espacio público: una nueva condición de la ciudad que también tuvo repercusiones en el comportamiento social de sus habitantes. Palabras clave: Urbanismo, arborización, riego, acequia, Mendoza, parques, árbol urbano, espacio público.

A characteristic of Mendoza's environment is the combination of a basic irrigation system, dating back to the first pre-Colom bian vegetable gardens and its tree-lined streets. In a basically dry climate, urban tree planting was crucial to appropriating the public space, creating a new condition in the city that also had an impact on the social behavior of its citizens.

Key words: Town planning, urban design, urban forestry, irrigation, drainage

La estructura urbana de Mendoza, una de las ciudades de mayor aglomeración al oeste de la República Argentina, es una de las fundaciones españolas en Sudamérica que contiene probablemente una de las tramas urbanas más complejas.

Este trabajo se focaliza en la conformación de dicha estructura, analizando cómo se fusionan las diferentes mallas que definen el tejido de la ciudad, originando áreas ambientalmente propicias para el desarrollo de la vida.

\section{Mendoza y la transformación de su estructura urbana}

La estructura urbana de Mendoza entremezcla tres tipos de mallas que se superponen en el espacio: una red hídrica desarrollada por los aborígenes de la zona y adoptada por los fundadores españoles; el damero característico de las ciudades fundacionales españolas y, por último, una malla que surge con posterioridad debido a la interacción de las dos primeras y que se relaciona con la aparición de una trama vegetal en la ciudad, inicialmente desarrollada al interior de los predios. Tanto la trama de acequias como la de vegetación fueron elementos característicos de la ciudad desde sus comienzos, delineando ciertos criterios de planificación.

\section{Mendoza ciudad oasis}

En la actualidad circula una imagen de Mendoza como ciudad oasis ${ }^{1}$, debido a la cantidad de forestales que incorpora la planificación urbana: pocas ciudades en el mundo han desarrollado un sistema de riego que se entremezcla a lo largo de la ciudad con la forestación que en sus márgenes se ha colocado.
Este aspecto particular de la ciudad en torno al arbolado urbano, conlleva a la suposición de un amplio conocimiento en la utilización del vegetal como elemento estético y fundamentalmente ambiental.

Como veremos, estos criterios no se desarrollaron conjunta y armónicamente. Aunque esta imagen es el punto de partida de nuestro interés, nos focalizaremos en conocer cómo en el proceso histórico de conformación de la estructura del verde urbano se relacionaron los criterios paisajísticos y ambientales.

\section{El verde urbano en Mendoza}

Si bien la evolución del verde urbano en la ciudad de Mendoza posee registros de una larga data, no se conoce una fecha oficial la cual se inicien las labores de forestación, las que surgen practicamente de la posibilidad de los colonizadores de utilizar el sistema de riego -creado por los huarpes y perfeccionado por los incas- para la irrigación inicial de huertas y abastecimiento de agua para beber en los solares que conformaban las cuadras del primer asentamiento poblacional, hacia 1562 (Ponte, 1998).

El uso de estas obras hidráulicas desarrolladas por los indígenas continua, prácticamente sin ampliación ni modificación, por más de cincuenta años ya que

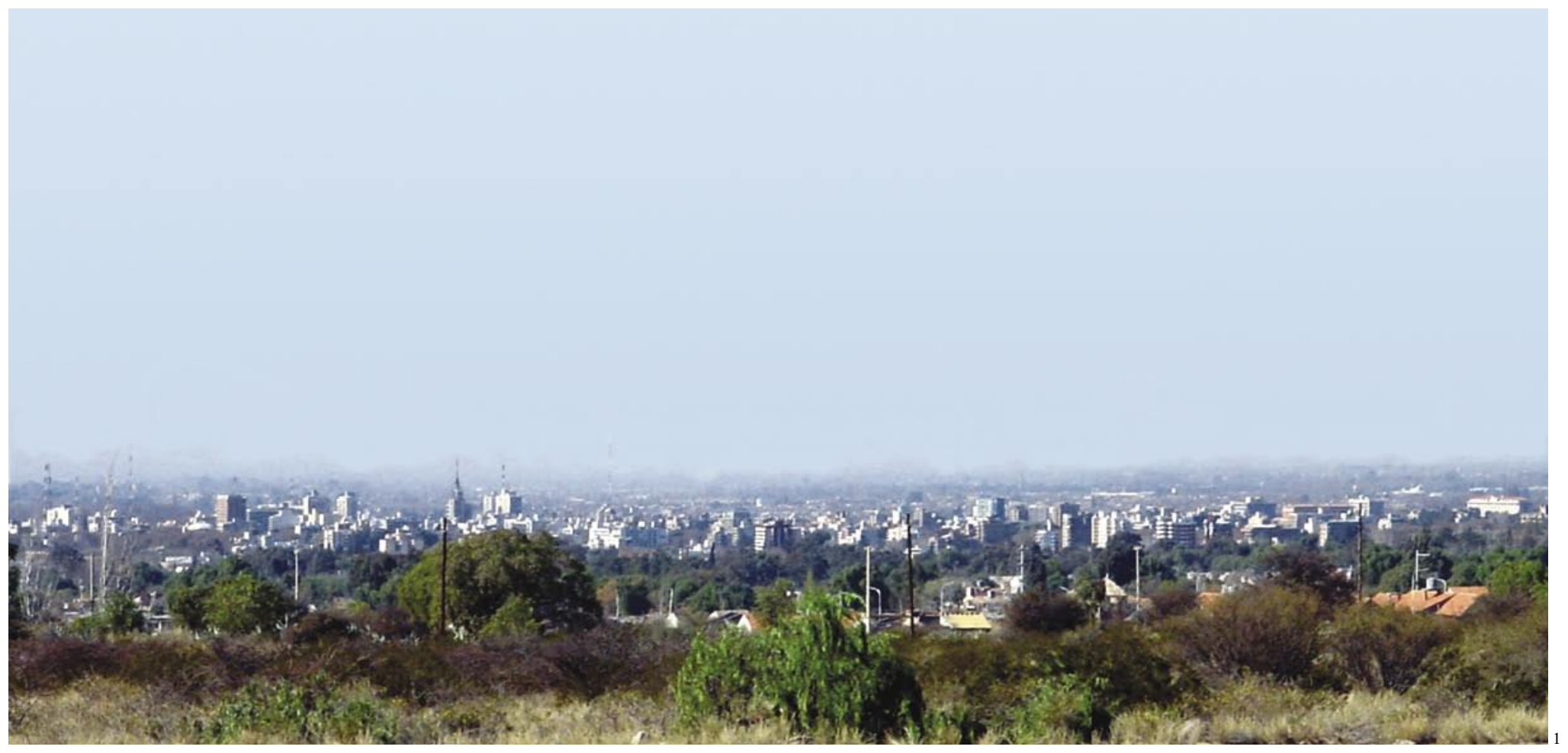




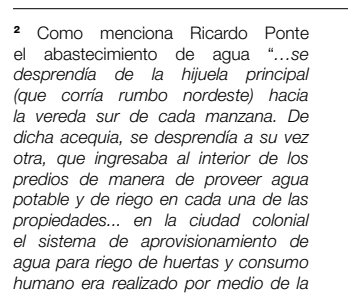

agua para riego de huertas y consumo
humano era realizado por medio de la misma red hidrica de canales que se ramificaban en una serie de acequias, de la pendiente del terreno" (Ponte, 1998). La posibilidad de manten irrigadas huertas hacia el interior de los terrenos es lo que posibilitó inicialment la aparición de forestales, principalmente de especies frutales hacia in interior delas sevolcaban visualmente hacia el exterior de las cuadras del primer asentamiento. Este proceso de forestación es al que denominamos inicialmente intra muros.
(Coni, 1918).
3 El término apropiación es utilizado como la acción de tomar algo, no de por el interés o necesidad que sino objeto despierta. ${ }^{4}$ La incorporación de estos espacios
verdes en la ciudad, actualmente responde a la distribución de cinco plazas denominadas plaza Independencia, plaza España, plaza
Chile y plaza San Martin.
1 Vista oeste desde el pie de monte, ciudad de Mendoza 2 Aerofotografía del centro, ciudad de Mendoza. Plazas Independencia, San Martín y España recién hacia 1610 la ciudad comenzó a consolidarse como un asentamiento poblacional definitivo.

En este primer período se observa que la planificación urbana responde a actividades propias de ciudades coloniales, relacionadas con la defensa y colonización de nuevos territorios; estas actividades se reflejan en la conformación del núcleo fundacional, dominado por un espacio central -la Plaza de Armas- donde el ejército puede realizar maniobras, y donde se puede desarrollar cómodamente el mercado. Prácticamente no existía lugar para la vegetación en los espacios públicos; en esta primera etapa el verde urbano es considerado solamente como una incipiente vegetación intra-muros ${ }^{2}$.

A inicios del siglo XVIII y con el crecimiento de la ciudad las acequias se trasladaron hacia el exterior de las cuadras; este elemento colector cambiar a su disposición varias veces desde el centro de las calles hasta sus márgenes. Se defini as uno de los espacios característicos de la ciudad de Mendoza: su perfil urbano, conformado por vereda, acequia, arbolado, calle, arbolado, acequia y vereda. Estos cursos de agua tuvieron un papel preponderante a fines del siglo XVIII, como instrumentos que impulsaron $y$ permitieron el desarrollo del verde al interior de la ciudad; la vegetación existente al interior de las cuadras comenzó a volcarse hacia el espacio público, aunque de una manera individual, sin una planificación integrada. El traslado de la vegetación intra-muros hacia el exterior de las viviendas facilitó e influyó en la apropiación ${ }^{3}$ del espacio público, hasta entonces desprovisto de todo uso social.

Como podemos observar, este proceso no se dio como una respuesta programada a las necesidades sociales y ambientales de la época, sino por la atracción que este nuevo espacio urbano despertó en la población. Los procesos que lo definieron y consolidaron tuvieron lugar con posterioridad, con el uso que los diferentes grupos le asignaron, transformándolo en lugar de encuentro.

El uso de estos espacios empezó a tener un significado simbólico que contribuyó a conformar la identidad de los diferentes sectores barriales, convirtiéndose hacia 1850 en espacios de gran significado social en la ciudad.

A partir de los efectos que se observaron en la incorporación del verde es que comenzó a considerarse como elemento de importancia en el ambiente urbano. No obstante, recién con lo sucedido en el terremoto de 1861 aparece en los trazados de la nueva ciudad la incorporación del verde urbano de manera planificada.

La incorporación del vegetal produjo una nueva transformación en la incipiente trama urbana. Un conjunto de espacios verdes ${ }^{4}$, conformados por una plaza central enmarcada por cuatro plazas menores en sus vértices, aumentó el número de áreas forestadas y espacios verdes. Se cree que este cambio respondió -aunque no existen documentos que amplíen estos conceptos- a la idea de disponer de espacios públicos dentro de la trama urbana donde poder evacuar a la población frente a posibles sismos.

Paralelo a la incorporación de estas áreas, comenzaron las modificaciones en la disposición del arbolado en las calles, considerándolos elementos de contención para posibles derrumbes de los frentes de las viviendas, a fin de mantener la libre circulación. Es en este período donde se puede ver claramente la incorporación del vegetal como parte planificada del equipamiento urbano. Hacia 1872, los espacios verdes comenzaron a ser sectores urbanos relevantes en la vida social de la elite mendocina. La atención se centró entonces en la falta de una planificación paisajística, relacionada con la ausencia de criterios estéticos. En este período se emprendió una intensa labor urbanística vinculada a la higiene, dando nacimiento

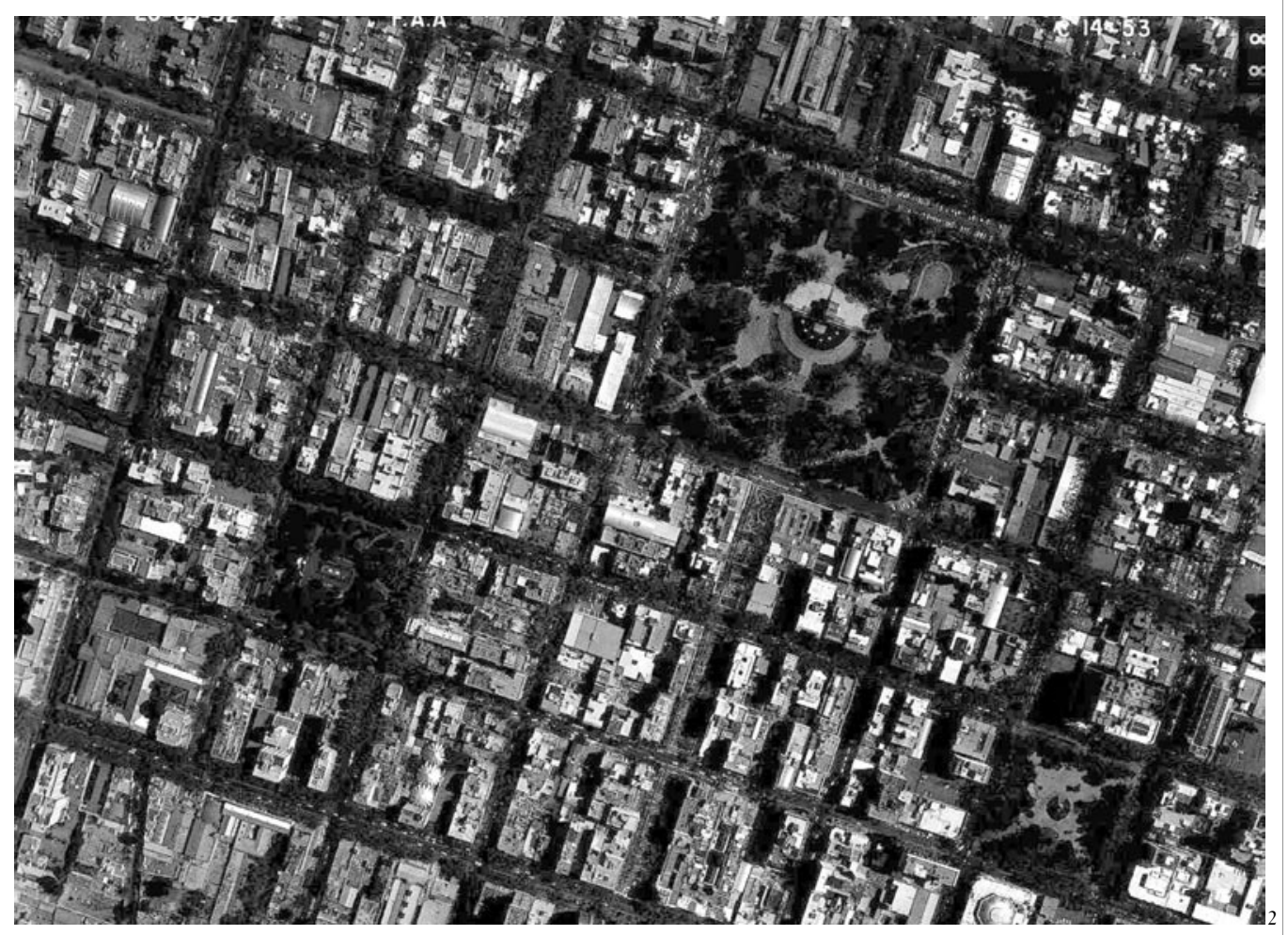




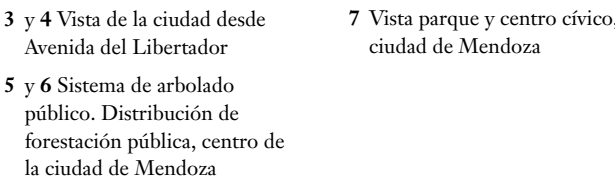

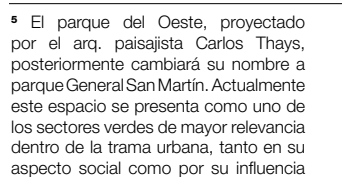
como por su influen (a)
'Diferentes especies vegetales como el álamo carolino tienen la capacidad de
enraizar sobre diferentes tipos de suelo debido a su atta propagación agámica, esto es el proceso mediante el cual
los tallos, los rizomas, las ramas, los rebrotes o cualquier otra parte activa de (l)
El arq. Ramos Correa durante su cargo como director de Parques $y$
Bosaues eliminarácercos, alambradosy balaustradas que cerraban visualmente al parque, generando una vinculación más directa con la ciudad y con el uso pubblico, satistaciendo nuevas recesidades sociales. A diferencia de lo social, ya no entiocado hacia la elite mendocina, sino más bien al conjunto de la socieda en la provincia al urbanismo bigienista que produjo grandes cambios en la ciudad de Mendoza; la clase dirigente, que procuró fundamentalmente " ...aggiornar la imagen de la ciudad y de borrar el pasado colonial; la intención muchas veces expresada, era la de asombrar al viajero" (Coni, 1896).

La idea de la clase dirigente de modificar la ciudad fue compartida y fortalecida por los profesionales que se dirigieron a Europa para instruirse y que a su regreso aportaron a la planificación local nuevos conceptos relacionados al urbanismo y al paisajismo. Floreció en Mendoza una nueva concepción moderna con relación a la modelación social y material del espacio, que se sustentó en los referentes de Francia e Inglaterra -que representaban la civilización- en oposición al pasado colonial, asociado a España, el atraso y la barbarie (Cirvini, 1996).

Se realizaron para ello grandes cambios constructivos, estéticos y especialmente paisajísticos. En esta etapa se comenzó a esbozar el desarrollo de un gran parque público en el pie de monte, vinculado visualmente a la ciudad con una gran avenida que, a modo de eje, conectaba aquel conjunto de plazas mencionadas anteriormente. Esta planificación, que dio origen al parque del Oeste ${ }^{5}$, inicialmente estuvo orientada a dar respuesta a requerimientos socioculturales y políticos, ligados a la consolidación de la identidad de una elite mendocina que anhelaba parecer culta y europeizada. Posteriormente, esta idea fue reforzada por requerimientos higiénicos introducidos por el Dr. Salas y plasmados por el Dr. Coni.

Hacia 1889 la ciudad de Mendoza comenzó a mostrar grandes falencias en aspectos higiénicos. A partir de un informe del Gobierno en 1896 sobre la situación sanitaria, se design al Dr. Coni para la implementación de un plan sanitario.

En este estudio se describe cómo el arbolado urbano había sido plantado sin ningún criterio científico (Coni, 1896) y que su estado respondía a la posibilidad de utilizar las acequias para su riego. En este mismo estudio se detalla también una serie de problemas relacionados con el estado de la forestación:

La deposición de materia orgánica en techos y acequias generaba focos de enfermedades, teniendo en cuenta que en este período todavía se usaban como fuente de abastecimiento de agua en gran parte de la ciudad.

Los techos de viviendas, realizados con barro, guano y caía, permitían que las ramas de los álamos ${ }^{6}$ que se depositaban en ellos se nutrieran y enraizaran.

La distribución de árboles cada cuatro metros generaba una bóveda sobre veredas y viviendas que dificultaba la aireación y el paso del sol; esto se modificó ampliando la distancia a diez metros. Esta modulación en la forestación ha continuado utilizándose hasta la fecha en urbanizaciones mendocinas (Coni, 1896).

Desde 1896 hasta 1903 se produjo un gran crecimiento a nivel paisajístico, con el inicio de la ejecución del parque del Oeste y la llegada del paisajista Carlos Thays, quien se encargó de su diseño y asesor el proyecto de renovación de arbolado público planteado por el Dr. Emilio Coni. Entre 1930 y 1950 comenzó el planteo de soluciones a problemas urbanos específicos: refuncionalización de la plaza Independencia, crecimiento del parque, creación del parque O’Higgins y también la ubicación del centro cívico. Si bien la incorporación de estos nuevos espacios incrementó las superficies forestadas dentro de la trama de la ciudad, la intención inicial no estuvo destinada a optimizar el ambiente urbano, sino a valorizar determinados sectores que comenzaron a tener una participación activa en la vida social de Mendoza, como su centro cívico. Con la creación de la Dirección de Parques y Bosques, y con la intervención como director de uno de los arquitectos más reconocidos en la provincia, Ramos Correas, se produjeron las remodelaciones más importantes a nivel estético desde la creación del parque Del Oeste, con una marcada orientación
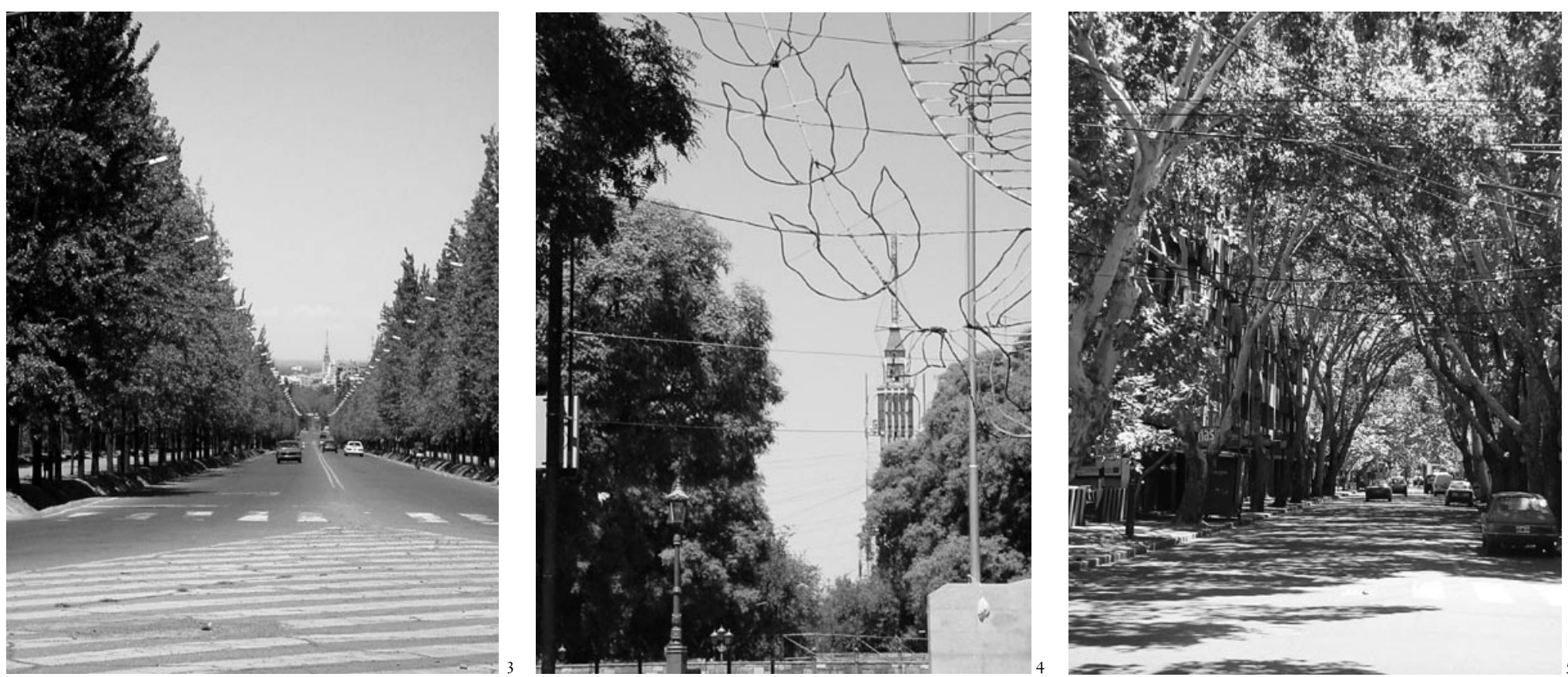
8 El desarrollo de técnicas

y materiales constructivos utilizados en la materialización del sistema de riego, permitio ir modificando su fisonomía de acuerdo a los diferentes elementos utilizados: desce el apisonado de tierra al empedrado, al empedrado con cemento, al hormigonado hast la incorporación de elementos estructurales sobre las acequias.
La última etapa de este proceso ocasiona una disociación entre el sistema de urbanización y el tejido vegetal, produciendo un déficit en el abastecimiento de nutrientes, en la infiltración de en la infltracion de agua y en e equilibrio de aire en las raíces, lo que debilita el bosque urbano y lo hace más propenso a ser afectado por diferentes plagas. hacia lo social ${ }^{7}$. Este período fue uno de los últimos en donde se elaboraron propuestas de forestación e intervenciones paisajísticas a nivel urbano.

En las décadas de los ochenta y noventa se desarrollaron estudios y proyectos para continuar con la incorporación de espacios verdes en la ciudad. En ellos se incluyeron nuevos criterios paisajísticos y fundamentalmente ambientales, pero al momento de su ejecución fueron modificados por los diferentes organismos gubernamentales, manteniendo solamente los criterios estéticos.

A partir de este período no se originaron otros avances a nivel paisajístico, y el uso e implementación del verde urbano continuó con los conceptos utilizados y desarrollados durante el siglo XIX. En los últimos años, el proceso de urbanización de la ciudad de Mendoza incorpora espacios verdes como respuesta a ordenanzas y leyes de loteo: especificaciones muy generales que debían cumplirse para la ejecución de todo proyecto, ya ni siquiera por razones estéticas, y menos aún ambientales.

\section{Conclusión}

Debemos manifestar que los conceptos paisajísticos incorporados a mediados del siglo XIX estuvieron destinados principalmente a fortalecer la identidad política de la clase dirigente, en lugar de dar soluciones a problemas ambientales de la época. Sin embargo, como efecto remanente de lo que se buscaba, el crecimiento paulatino del bosque urbano ocasionó una optimización del ambiente que permitió entrever los beneficios que la arborización aportaba, más allá de su cualidad estética.

El interés declarado por el vegetal recién se consolidó hacia fines del siglo XIX, cuando es percibido como un elemento relevante en el tejido urbano. Paradójicamente, es entonces cuando el sistema de urbanización -dominado por el uso de materiales como el hormigón- prácticamente se consolida. En la actualidad, este dominio en las operaciones urbanísticas produce un desequilibrio entre elementos construidos y la vegetación, en claro desmedro de esta última y del abastecimiento de sus requerimientos nutricionales. Además, la incorporación reiterada de conceptos desarrollados décadas atrás aleja a la planificación de espacios verdes de los requerimientos de una ciudad en constante proceso de cambio.

Advertimos así que en la planificación de espacios verdes no debe ponderar solamente su aspecto estético; más bien atender a su condición de lugares privilegiados para controlar los conflictos ambientales que el proceso urbanizador genera, especialmente en ciudades con climas desérticos. ARQ
Bibliografía: Breuste J., Feldmann H., Uhlmann O. Urban ecology. Springer-Verlag, Heidelberg, 1998. / Coni, Emilio; Saneamiento de la ciudad de Mendoza. Imprenta Pablo E. Coni e Hijos, Buenos Aires, 1896. / Coni, Emilio; Memorias de un médico bigienista. Talleres Gráficos A. Flaivan, Buenos Aires, 1918. / Castillo, Adriana; Década. Diez años de gestión ambiental en Mendoza. Ministerio de Medio Ambiente y Obras Públicas, Gobierno de Mendoza, Mendoza, 1999. / Cirvini, Silvia; "El Paseo del Oeste: de paseo aristocrático a parque popular”. En Nallín, C., Díaz Araujo, E., Ponte, J.R. et. al; Centenario Parque General San Martín. Tomo 1, Zeta Editores, Mendoza, 1996, p. 53. / Fernández, Roberto; La ciudad verde. Programa Editorial del CIAM, Mar del Plata, 1998. / Gates, D.M; Man and his environment climate. Harper \& Row Publishers, Nueva York, 1972. / Golany, Gideon et. al.; Planificación urbana en zonas áridas. Editorial Limusa, México, 1984. / Leff, Enrique; Ecología y capital. Siglo Veintiuno Editores, Méjico, 1998. / Miller, R.; Urban forestry: planning and managing urban greenspaces. Englewood Cliffs, Nueva Jersey, 1988. / Ponte, Ricardo et. al.; Mendoza, donde las acequias encauzan la bistoria. Zeta Editores, Mendoza, 1998. / Ponte, Ricardo; Mendoza aquella ciudad de barro. Imprenta municipal de la ciudad de Mendoza, Mendoza, 1987, pp. 42-43. / Pridema; II jornadas internacionales multidisciplinarias sobre medio ambiente. Volumen I y II, Edium, Mendoza, 1991. / Tacchini, J., S. de Mor n, A. et. al.; Mendoza en el 2000. Inca Editorial, Mendoza, 1994. / V.V.A.A., Fundación Banco Boston; La ciudad de Mendoza a través de cinco temas. Talleres Gráficos Faija Hnos., Buenos Aires, 1991.
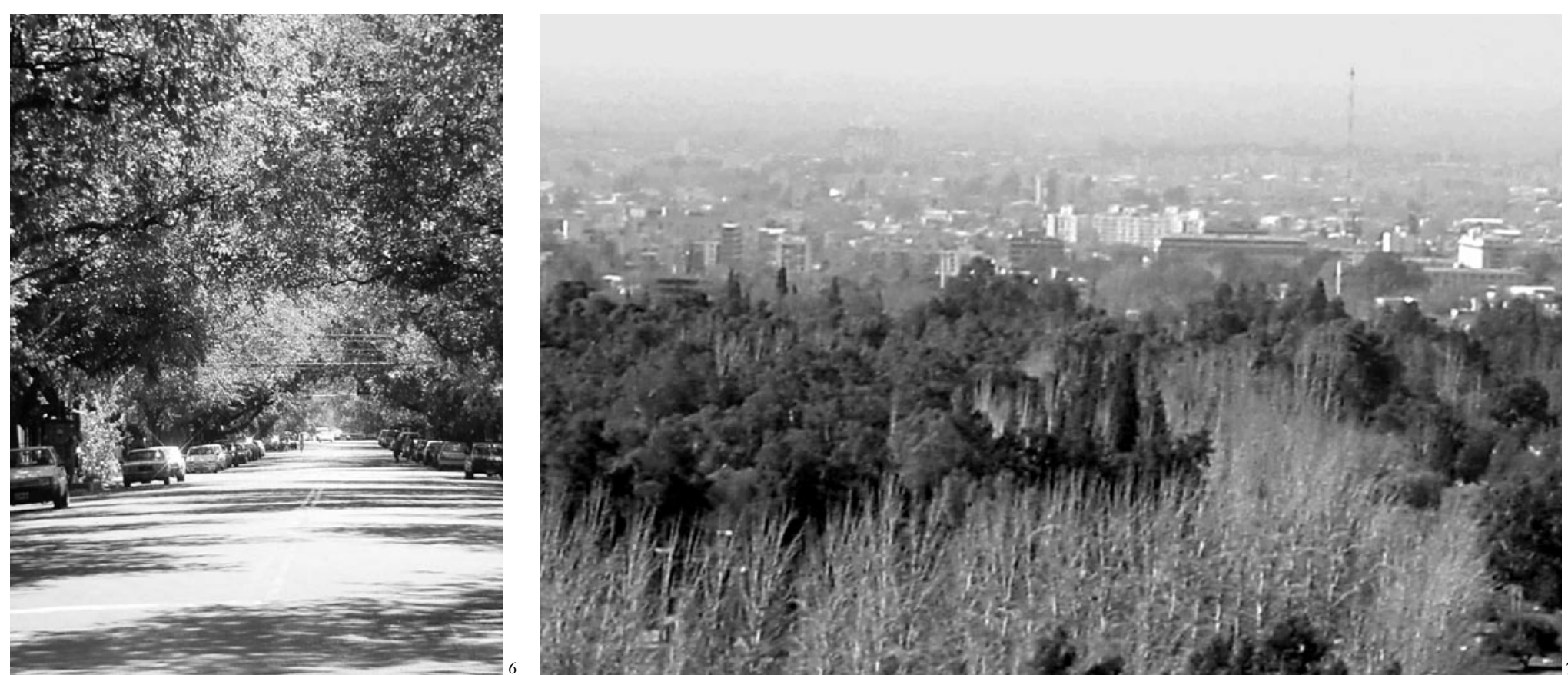